\title{
Long-term follow-up study of the malignant transformation potential of the simple renal cysts
}

\author{
Bicheng Yang ${ }^{1 \#}$, Chunhua Qiu ${ }^{2 \#}$, Shawpong Wan ${ }^{1}$, Jianhua Liu' ${ }^{2}$ Qingxiu Li ${ }^{1}$, Zanlin Mai ${ }^{1}$, Tao Zeng ${ }^{1}$, \\ Yang Liu ${ }^{1}$, Weizhen $\mathrm{He}^{3}$, Guohua Zeng ${ }^{1}$ \\ ${ }^{1}$ Department of Urology, Minimally Invasive Surgery Center, the First Affiliated Hospital of Guangzhou Medical University, Guangdong Key \\ Laboratory of Urology, Guangzhou 510230, China; ${ }^{2}$ Department of Medical Ultrasound, Guangzhou First People's Hospital, South China \\ University of Technology, Guangzhou 510080, China; ${ }^{3}$ Health Screen Center, Shaoyang Central Hospital, Shaoyang 422000, China \\ Contributions: (I) Conception and design: B Yang, S Wan, G Zeng; (II) Administrative support: J Liu, Q Li, W He, G Zeng; (III) Provision of study \\ materials or patients: J Liu, Q Li, W He, G Zeng; (IV) Collection and assembly of data: B Yang, Q Li, Z Mai, T Zeng, Y Liu; (V) Data analysis and \\ interpretation: B Yang, Q Li; (VI) Manuscript writing: All authors; (VII) Final approval of manuscript: All authors. \\ \#These authors contributed equally to this work. \\ Correspondence to: Zeng Guohua. Department of Urology, Minimally Invasive Surgery Center, the First Affiliated Hospital of Guangzhou Medical \\ University, Guangdong Key Laboratory of Urology, Guangzhou 510230, China. Email: gzgyzgh@vip.sina.com.
}

Background: We conducted a multi-center study to investigate the prevalence, the malignant
transformation potential of the simple renal cysts and the factors that might predict malignancy.
Methods: We defined the simple renal cysts as Bosniak class I \& II (including IIF) lesions. In the
prevalence study, data from 115,132 ultrasonographies was collected from individuals who participated in a
multiphasic health wellness screen. In the natural history and progression study, we retrospectively reviewed
333 participants with simple renal cysts and were followed for at the least 3 years with a mean of $6.3 \pm 2.9$
years (ranged from 3 to 13 years). Results: About $7.2 \%(8,303)$ of the individuals who participated in the study were found to have at the least one simple renal cyst. The incidence increased with age from $0.6 \%$ in the first decade to $28.0 \%$ in the eighth or later decade of life. The Bosniak class I lesion accounted for 7,559 or $91.0 \%$ of the cysts whereas 744 or 9.0\% were class II. A slower growth rate was observed in the older age group. Twenty-four patients (7.2\%) had their renal cysts upgraded according to the Bosniak classification. Gender, age, initial cyst size, number of cysts and bi-laterality failed to predict the malignancy tendency.

Conclusions: Most of the cysts discovered were the Bosniak class I and II lesions and they rarely progress further. Treatment for the asymptomatic simple renal cyst is not warranted. Treatment decision-making based on older age or larger initial cyst size should not be recommended.

Keywords: Renal cyst; prevalence; Bosniak classification; natural history

Submitted Jan 07, 2020. Accepted for publication Feb 29, 2020.

doi: $10.21037 /$ tau.2020.03.29

View this article at: http://dx.doi.org/10.21037/tau.2020.03.29

\section{Introduction}

Renal cysts are commonly observed in human kidneys. Most renal cysts are found incidentally during radiological or sonographic examination of the abdomen and they are rarely symptomatic (1-3). The Bosniak classification has been accepted by both radiologists and urologists as a means to estimate the malignancy for renal masses, in which class IV lesions are cystic malignant tumors (4). Large percentages of the renal cysts in China were found by the ultrasonographic study of the abdomen as part of routine wellness health screen. Recent studies suggested ultrasound was the best screening tool for the Bosniak I and II cysts and had excellent correlation with the CT images $(5,6)$.

There is a lack of large population based data on the 
nature history and the prevalence of renal cysts. There is also no long term follow up of the simple renal cysts based on the Bosniak classification. Often, treatment decisions were made with inadequate information or even misconceptions (7). Invasive interventions such as surgical decortication or marsupialization and percutaneous aspiration of the renal cyst were commonly performed, even for asymptomatic simple renal cysts (8).

It is reported larger cysts tend to grow more rapidly (1). But no data clarified whether larger size or older age predicts the risk of malignancy. Patient age and cyst diameter were still regularly used as indications for treatment $(8,9)$. In a recent case report of 31 cases of renal cell carcinoma derived from simple renal cyst, the authors even urged regular follow-up and timely surgical treatment for simple renal cyst (10). But studies had demonstrated that serious complications had occurred with these interventions and some of those complications turned out to be even lifethreatening $(11,12)$.

In our current study, we aimed to investigate the Bosniak class progression and to identify factors, including patient age and cyst diameter, which would predict the malignancy of simple renal cysts. We also assessed the prevalence, the Bosniak class distribution and sequential size changes of these cysts.

\section{Methods}

This study was approved by the Ethics Review Board of The Guangzhou Medical University in Guangzhou, China (ethical approval number: 20121226-01). In addition, written informed consents were obtained from all the patients. For the minors/children, written informed consents were obtained from the next of kin, caretakers, or guardians.

From January to December in 2013, a total of 115,132 individuals who participated in the health wellness screens and also had abdominal ultrasonographic examinations as part of those screenings constituted the study cohorts. These health wellness screens took place at three centers in the southern China provinces. The ages of the patients ranged from 14 days to 94 years old with a mean age of $47.3 \pm 16.9$ years. The male to female rate was 1.2:1. Patients who had a diagnosis of renal cyst were identified and their ultrasound findings were reviewed. Patients with dysplastic kidney, polycystic kidney disease, and patients who had prior surgical procedure on the kidney were excluded from the study. We defined Bosniak class I and II (including IIF) lesions as simple renal cysts in our study. The following criteria were adopted for the Bosniak classification. Bosniak I: Round, smooth thin walled cyst, no echogenic foci or enhancement throughout the transmission of the ultrasound. Bosniak II (and IIF): Cyst with fine calcifications or thin septum or septa with or without minimal or smooth thickening of the cyst wall or septation(s) $(4,13)$. Lesion size was estimated by using the largest cyst diameter. Individual with multiple cysts, the highest Bosniak classification was entered for the analysis. We then investigated the prevalence, age, gender and Bosniak class distribution.

From January 2005 to December 2018, we identified 333 individuals who were diagnosed with simple renal cysts that were followed for at the least 3 years, with a mean of $6.3 \pm 2.9$ years. The participants were 21 to 94 years old at the diagnosis. The age and the gender distributions were shown in Table 1. The ultrasound follow-up was performed at one-year intervals. The largest diameter of the cyst or cysts per renal unit was measured. Comparison of the sequential changes was performed by selecting the nearest identical images from the previous study. All the ultrasounds were performed by the senior ultrasonographer in each of the centers using static gray scale and real time B-mode ultrasonographic unit with a 3.5 or $5 \mathrm{MHz}$. transducer.

Quantitative variables were compared using the Kruskal-Wallis $\mathrm{H}$ test and the Mann-Whitney $\mathrm{U}$ test when indicated. The chi-square test was performed to compare the categorical variables. Logistic regression was used to examine the relationship between the dependent variable and the potential variables. $\mathrm{P}<0.05$ was considered statistically significant.

\section{Results}

In the prevalence survey, at the least one simple renal cyst was detected in 8,303 individuals among the 115,132 participants in the study, an overall prevalence rate of $7.2 \%$. A male dominant ratio of $2.6: 1$ was observed $(9.7 \%$ in male vs. $4.4 \%$ in female $)(\mathrm{P}<0.001)$. The prevalence increased with age $(\mathrm{P}<0.001)$, from $0.6 \%$ in the first decade of life to $28.0 \%$ in the 8 th or later decade of life. The incidence of cyst was found to increase in each sequential decade $(\mathrm{P}<0.001)$ with the exception of the first three decades. Individuals with renal cysts were significantly older in both male $(\mathrm{P}<0.001)$ and female $(\mathrm{P}<0.001)$ than those without cysts. Furthermore, the male dominance remained in all the age groups $(\mathrm{P}<0.001)$ except the first two decades.

About $91.0 \%(7,559)$ cysts were found to be in the Bosniak class I and 744 (9.0\%) in the Bosniak class II (Table 2). Individuals with multiple $(\mathrm{P}<0.001)$ or bilateral cysts $(\mathrm{P}<0.001)$ had higher Bosniak classification. Interestingly, the Bosniak class I individuals were older than the class II 
Table 1 The incidence of renal cysts in 115,132 patients

\begin{tabular}{lrrr}
\hline Age & Male (\%) & Female (\%) & Total (\%) \\
\hline $0-10$ & $6(0.57)$ & $4(0.55)$ & $10(0.56)$ \\
$11-20$ & $8(0.87)$ & $7(1.09)$ & $15(0.98)$ \\
$21-30$ & $119(1.56)$ & $59(0.73)$ & $178(1.13)$ \\
$31-40$ & $367(3.02)$ & $146(1.31)$ & $513(2.20)$ \\
$41-50$ & $810(5.45)$ & $341(2.60)$ & $1,151(4.12)$ \\
$51-60$ & $1,068(10.68)$ & $495(5.23)$ & $1,563(8.03)$ \\
$61-70$ & $1,268(17.25)$ & $481(9.15)$ & $1,749(13.87)$ \\
$71-80$ & $1,678(27.40)$ & $541(16.07)$ & $2,219(23.38)$ \\
81 and older & $684(32.29)$ & $235(20.17)$ & $919(27.99)$ \\
Total & $6,008(9.66)$ & $2,309(4.36)$ & $8,317(7.22)$ \\
\hline
\end{tabular}

Table 2 The distribution of the Bosniak classes of 8,317 renal cysts

\begin{tabular}{lcccc}
\hline Age & Class I (\%) & Class II (\%) & Class III (\%) & 0 \\
\hline $0-10$ & $10(0.56)$ & 0 & 0 & 0 \\
$11-20$ & $15(0.98)$ & 0 & 0 & 0 \\
$21-30$ & $148(0.94)$ & $30(0.19)$ & 0 & 0 \\
$31-40$ & $425(1.83)$ & $88(0.38)$ & 0 & 0 \\
$41-50$ & $1,002(3.58)$ & $149(0.53)$ & $9(0.05)$ & 0 \\
$51-60$ & $1,376(7.07)$ & $178(0.91)$ & $2(0.02)$ & $1(0.01)$ \\
$61-70$ & $1,608(12.75)$ & $138(1.09)$ & $1(0.03)$ & 0 \\
$71-80$ & $2,093(22.05)$ & $125(1.32)$ & $13(0.01)$ & $1(0.0009)$ \\
81 and Older & $882(26.87)$ & $36(1.10)$ & $744(0.65)$ & 0 \\
Total & $7,559(6.57)$ & $0.008)$ & \\
\hline
\end{tabular}

The percentage represented the percentage of renal cyst patients in each age group.

$(\mathrm{P}<0.001)$. No significant difference in the Bosniak category was found between the male and the female $(\mathrm{P}=0.3)$. There was no significant difference in the initial diameter of the cyst between the class I and class II $(\mathrm{P}=0.6)$. Multivariate logistic analysis using age (Wald $=74.3, \mathrm{OR}=0.9, \mathrm{P}<0.001$ ), cyst number (single or multiple, Wald $=9.4, \mathrm{OR}=1.6$, $\mathrm{P}=0.002$ ), and bi-laterality (unilateral vs. bilateral, Wald $=24.7, \mathrm{OR}=2.1, \mathrm{P}<0.001$ ) as variables revealed that all these three parameters were correlated with the Bosniak classification.

We identified 333 individuals with simple renal cysts who had been followed from 3 to 13 years (mean 6.3 \pm 2.9 years). The male-to-female ratio was 2.58:1. The mean age was $61.1 \pm 16.8(21-94)$ years old. The mean diameter was $25.2 \pm 14.3 \mathrm{~mm}$. During the follow up, $261(78.4 \%)$ cysts increased in size; $62(18.6 \%)$ cysts decreased; and $10(3.0 \%)$ cysts remained stable. No age difference was found among the individuals with the cysts that increased in size $(\mathrm{P}=0.8)$ or the individuals with the cysts that decreased in size $(\mathrm{P}=0.6)$ from the rest of the cohorts.

In order to study the variations between different age groups, we divided these individuals into two age groups (21-60 years and 61 years or older). The annual increase in the diameter was $1.8 \pm 1.5 \mathrm{~mm}$ in the $21-60$ years and $1.3 \pm$ $1.0 \mathrm{~mm}$ in the 61-94 years. A slower growth in term of cyst diameter was observed in the older age group $(\mathrm{P}=0.003)$. A 
Table 3 Cyst characteristics that might predict the progression of the Bosniak class in the follow-up study

\begin{tabular}{lcc}
\hline Factors & $\mathrm{MWU} / \chi^{2}$ test & Logistic regression \\
\hline Gender & $\mathrm{P}=0.7$ & \\
Age & $\mathrm{P}=0.04$ & Wald $=3.5, \mathrm{OR}=1.0, \mathrm{P}=0.06$ \\
Cyst size & $\mathrm{P}=0.9$ & \\
Cyst number & $\mathrm{P}=0.3$ & \\
Bi-laterality & $\mathrm{P}=0.3$ & \\
\hline
\end{tabular}

MWU, Mann-Whitney U test.

faster growth of $1.7 \pm 1.4 \mathrm{~mm}$ was observed in the larger cysts (no less than $21 \mathrm{~mm}$ ) as compared to $1.3 \pm 1.1 \mathrm{~mm}$ of the smaller cysts $(<21 \mathrm{~mm}), \mathrm{P}=0.01$. No significant difference in the annual growth rate was found between the men and the women $(\mathrm{P}=0.8)$, the multiple $v$ s. the single cysts $(\mathrm{P}=0.3)$, and the bilateral vs. the unilateral cysts $(\mathrm{P}=0.7)$.

To investigate the malignancy potential of the renal cysts, the Bosniak class was compared in the follow-up study. 317 (95.2\%) of the cysts were initially assigned to the Bosniak class I and $16(4.8 \%)$ to class II. During the follow up, the class of 309 cysts $(92.8 \%)$ remained unchanged. 24 (7.2\%) cysts increased in the Bosniak category. They were all class I upgraded to class II. It should be noted that no simple renal cyst ever progressed beyond the Bosniak class II.

To determine the cyst characteristics that might predict the progression of the Bosniak class, we analyzed the following parameters: gender, age, initial cyst size, number of cysts (solitary or multiple), and bi-laterality (unilateral or bilateral) (Table 3). We found the individuals with cyst progression from the Bosniak class I to class II tended to be older $(\mathrm{P}=0.04)$. However, the age failed to be a significant predictor for the Bosniak class progression in the logistic regression analysis (Wald =3.5, OR =1.0, $\mathrm{P}=0.06$ ). No significant difference was observed between the individuals with progression and those who did not in the terms of gender, initial cyst diameter, number of cysts, or bi-laterality.

\section{Discussion}

Simple renal cysts are common and are often discovered incidentally during imaging studies. Symptoms such as abdominal mass, flank pain, and hematuria may occur occasionally (14). In a controlled epidemiological study of over 1,500 individuals, the prevalence of hypertension, flank pain, erythrocytosis, hematuria, and proteinuria was the same in the individuals with simple renal cysts and those without. The authors indicated that the association of these symptoms with renal cysts might be merely coincidental (15). The possible relationship between simple renal cyst and hypertension $(16,17)$ or renal dysfunction $(18,19)$ had been vigorously studied but the findings remained controversial. As we know, the incidence of hypertension and renal dysfunction increases with age and is different between genders (20). The same is true for the renal cyst $(1,2,14)$.

Image guided percutaneous needle aspiration with or without sclerosing agent and laparoscopic decortication or marsupialization are popular procedures employed for the treatment of renal cysts. Neither procedure however is as benign as it often being promoted. Simple percutaneous drainage is associated with a high percentage (30-80\%) of fluid re-accumulation. With the sclerosing agent, a recurrent rate as high as $30 \%$ has been reported. Complications from laparoscopic renal cyst decortication or marsupialization was reported to be $3-15 \%$. Complications included bleeding, hematoma, urinoma, peritonitis, port infection, postoperative ileus, and calyceal injuries (21-23). Finally death had known to occur with the renal cyst surgery.

Laucks and McLachlan (24) observed simple renal cysts in 25 of 103 patients $(24.3 \%)$ on computerized tomography (CT). Terada et al. (2) reported $11.9 \%$ participants had at the least one renal cyst on ultrasonography in a multiphasic health screening program. Our data showed the overall prevalence of simple renal cysts was $7.2 \%$ (8,303 of 115,132 individuals). It should be noted that the populations participating in health screening $(1,2)$ showed a lower prevalence of renal cyst than the populations who were hospitalized or followed at clinics $(15,25)$. In addition, the prevalence of renal cyst detected by CT (24) was higher than the prevalence detected by ultrasonography (26). It was estimated that $20 \%$ of the population by the age of 40 years, and as high as $50 \%$ by the age of 60 years harbored renal cysts $(1,2,26)$. In our study, the incidence of the simple renal cyst increased with age $(\mathrm{P}<0.001)$, from $0.6 \%$ in the 1 st decade of life to $28.0 \%$ in the eighth or later decade of life. Most of previous reports showed no gender predilection in the prevalence of renal cyst. However, it had also been reported that men were afflicted more often than women with the renal cyst, ranging 1.6-2:1 (1,2,14). A clear male predominance was observed $(9.7 \%$ in male vs. $4.4 \%$ in female) in our study $(\mathrm{P}<0.001)$. Furthermore, we found that most of the age groups exhibited this male dominance $(\mathrm{P}<0.001)$ with the exception of the first two decades of life. The cause of this predilection in the adult males might merit further investigation.

Studies had indicated that renal cysts increased with age 
and tended to progress in size (1-3). Marumo et al. (25) investigated the growth pattern of simple renal cysts in the asymptomatic microscopic hematuria patients. The annual growth rate of the mean maximum diameter was $4.2 \%$ during a 3 -year follow-up period in 55 patients, and $5.1 \%$ during a 6-year follow-up in 31 patients (2). Another study of the asymptomatic renal cyst patients with longterm follow-up showed that the diameter of a renal cyst could increase by $1.6 \mathrm{~mm}$ or about $5 \%$ annually (1). Multiloculated cysts grew more rapidly than the simple cysts. Bilateral cysts tended to be more aggressive when compared to the unilateral ones $(1,2,25)$. Previous reports suggested that cyst aggressiveness was predicted by age, cyst shape and bi-laterality $(1,2,25)$. Due to the obscurity of the actual time of the cyst formation and the chronic nature of the renal cyst, the issue of whether the cysts did grow slower with time was difficult to quantify. However, a slower growth in older individuals was corroborated in our study.

It is known that malignancies are common in the Bosniak class III or IV renal cysts $(4,13,27,28)$. Previous studies showed approximately $40-60 \%$ of the class III and $85-100 \%$ of the class IV cysts were malignant $(29,30)$. Only a few studies had reported malignant transformation of the simple renal cysts. These studies were mainly case reports. Qin et al. (10) reported 31 cases of renal cell carcinoma derived from simple renal cyst. This study however did not contain any data about the probability of malignancy developed from the simple renal cyst. In a prospective study of 61 patients with simple renal cysts followed for up to 14 years, only two developed renal neoplasms that might be related to the renal cyst (1). These studies demonstrate the reliability of the Bosniak classification. In our prevalence survey, 7,559 (91.0\%) cysts were of the Bosniak class I and 744 (9.0\%) the class II. In the follow-up study, the class of most of the cysts remained unchanged. Only 24 (7.2\%) cysts upgraded from class I to II. Most importantly, none of the cysts ever progressed into class III. Moreover, we found gender, age, initial cyst size, number of cysts and bi-laterality did not predict the malignancy tendency. So it is arbitrary to make clinical decision based on older age or bigger cyst size.

We recognized several limitations to our study. All the problems were inherent to the retrospective nature of this study that might influence the results. The differences in the operators and the ultrasonographic devices used in this multi-center study were also not accounted for. We did not have the pathological findings to confirm the reliability of the Bosniak classification. Furthermore, the results were not from a random population. There existed the bias toward the individuals who elected to participate in the multiphasic health screen.

\section{Conclusions}

Age and the diameter of the cyst have no significant relationship to the malignancy. The growth rate of simple renal cyst will decrease with age. Most of the renal cysts are the Bosniak class I lesions and they rarely progress. Treatment for the asymptomatic simple renal cyst is not warranted.

\section{Acknowledgements}

The authors would like to thank Stephanie Wan for the language polishing.

Funding: This work was financed by a grant from Science and Technology Project in Guangzhou (the People's Livelihood Special Major Science and Technology) (No.201300000096).

\section{Footnote}

Conflicts of Interest: All authors have completed the ICMJE uniform disclosure form (available at http://dx.doi. org/10.21037/tau.2020.03.29). The authors have no conflicts of interest to declare.

Ethical Statement: The authors are accountable for all aspects of the work in ensuring that questions related to the accuracy or integrity of any part of the work are appropriately investigated and resolved. This study was approved by the Ethics Review Board of The Guangzhou Medical University in Guangzhou, China (ethical approval number: 20121226-01).Written informed consents were obtained from all the patients.

Open Access Statement: This is an Open Access article distributed in accordance with the Creative Commons Attribution-NonCommercial-NoDerivs 4.0 International License (CC BY-NC-ND 4.0), which permits the noncommercial replication and distribution of the article with the strict proviso that no changes or edits are made and the original work is properly cited (including links to both the formal publication through the relevant DOI and the license). See: https://creativecommons.org/licenses/by-nc-nd/4.0/.

\section{References}

1. Terada N, Arai Y, Kinukawa N, et al. The 10-year natural 
history of simple renal cysts. Urology 2008;71:7-11; discussion 11-2.

2. Terada N, Ichioka K, Matsuta $\mathrm{Y}$, et al. The natural history of simple renal cysts. J Urol 2002;167:21-3.

3. Bayram MT, Alaygut D, Soylu A, et al. Clinical and radiological course of simple renal cysts in children. Urology 2014;83:433-7.

4. Bosniak MA. The Bosniak renal cyst classification:25 years later. Radiology 2012;262:781-5.

5. Peng Y, Jia L, Sun N, et al. Assessment of cystic renal masses in children: comparison of multislice computed tomography and ultrasound imaging using the Bosniak classification system. Eur J Radiol 2010;75:287-92.

6. Zhong J, Cao F, Guan X, et al. Renal cyst masses (Bosniak category II-III) may be over evaluated by the Bosniak criteria based on MR findings. Medicine (Baltimore) 2017;96:e9361.

7. Smith AD, Carson JD, Sirous R, et al. Active Surveillance Versus Nephron-Sparing Surgery for a Bosniak IIF or III Renal Cyst: A Cost-Effectiveness Analysis. AJR Am J Roentgenol 2019;212:830-8.

8. Lai S, Jiao B, Wang X, et al. Renal cell carcinoma originating in the free wall of simple renal cyst: Two unusual case reports with literature review. Medicine (Baltimore) 2019;98:e15249.

9. Liu W, Zhang C, Wang B, et al. Randomized study of percutaneous ureteroscopic plasma column electrode decortication and laparoscopic decortication in managing simple renal cyst. Transl Androl Urol 2018;7:260-5.

10. Qin X, Ye L, Zhang H, et al. Complicated variation of simple renal cyst usually means malignancy: results from a cohort study. World J Surg Oncol 2014;12:316.

11. Chen ML, Tomaszewski JJ, Matoka DJ, et al. Management of urine leak after laparoscopic cyst decortication with retrograde endoscopic fibrin glue application and ureteral stent placement. J Endourol 2011;25:71-4.

12. Shao Q, Xu J, Adams T, et al. Comparison of aspirationsclerotherapy versus laparoscopic decortication in management of symptomatic simple renal cysts. J Xray Sci Technol 2013;21:419-28.

13. Israel GM, Bosniak MA. An update of the Bosniak renal cyst classification system. Urology 2005;66:484-8.

14. Eknoyan G. A clinical view of simple and complex renal cysts. J Am Soc Nephrol 2009;20:1874-6.

15. Caglioti A, Esposito C, Fuiano G, et al. Prevalence of symptoms in patients with simple renal cysts. BMJ 1993;306:430-1.

16. Chin HJ, Ro H, Lee HJ, et al. The clinical significances of simple renal cyst: Is it related to hypertension or renal dysfunction? Kidney Int 2006;70:1468-73.

17. Veroux P, Veroux M, Puliatti C, et al. Living transplantation using a kidney with a large cyst as curative treatment of donor's hypertension. Nephrol Dial Transplant 2002;17:2258-60.

18. Al-Said J, O'Neill WC. Reduced kidney size in patients with simple renal cysts. Kidney Int 2003;64:1059-64.

19. Al-Said J, Brumback MA, Moghazi S, et al. Reduced renal function in patients with simple renal cysts. Kidney Int 2004;65:2303-8.

20. Wolf-Maier K, Cooper RS, Banegas JR, et al. Hypertension prevalence and blood pressure levels in 6 European countries, Canada, and the United States. JAMA 2003;289:2363-9.

21. Dunn MD, Clayman RV. Laparoscopic management of renal cystic disease. World J Urol 2000;18:272-7.

22. Fahlenkamp D, Rassweiler J, Fornara P, et al. Complications of laparoscopic procedures in urology: experience with 2,407 procedures at 4 German centers. J Urol 1999;162:765-70, discussion 770-1.

23. Liapis D, de la Taille A, Ploussard G, et al. Analysis of complications from 600 retroperitoneoscopic procedures of the upper urinary tract during the last 10 years. World $\mathbf{J}$ Urol 2008;26:523-30.

24. Laucks SP Jr, McLachlan MS. Aging and simple cysts of the kidney. Br J Radiol 1981;54:12-4.

25. Marumo K, Horiguchi Y, Nakagawa K, et al. Incidence and growth pattern of simple cysts of the kidney in patients with asymptomatic microscopic hematuria. Int J Urol 2003;10:63-7.

26. Tada S, Yamagishi J, Kobayashi H, et al. The incidence of simple renal cyst by computed tomography. Clin Radiol 1983;34:437-9.

27. Bosniak MA. The current radiological approach to renal cysts. Radiology 1986;158:1-10.

28. Graumann O, Osther SS, Osther PJ. Characterization of complex renal cysts: a critical evaluation of the Bosniak classification. Scand J Urol Nephrol 2011;45:84-90.

29. Bisceglia M, Galliani CA, Senger C, et al. Renal cystic diseases: a review. Adv Anat Pathol 2006;13:26-56.

30. Hartman DS, Choyke PL, Hartman MS. From the RSNA refresher courses: a practical approach to the cystic renal mass. Radiographics 2004;24 Suppl 1:S101-15.

Cite this article as: Yang B, Qiu C, Wan S, Liu J, Li Q, Mai Z, Zeng T, Liu Y, He W, Zeng G. Long-term follow-up study of the malignant transformation potential of the simple renal cysts. Transl Androl Urol 2020;9(2):684-689. doi: 10.21037/ tau.2020.03.29 